\title{
Synthesis, the structure of arylsalicylic amides, which have anthelmintic activity
}

\author{
(C) Anna Yu. Malakhova, and Vladimir N. Kuklin* ${ }^{+}$ \\ Department of Pharmaceutical Chemistry. St. Petersburg Chemical and Pharmaceutical Academy. \\ Prof. Popova St., 14, Lit. A. St. Petersburg, 197376. Russia. \\ Phone: +7 (812) 234-13-59, (812) 499-39-00 ext.4080.E-mail: kuklin-prof@yandex.ru
}

\begin{abstract}
*Supervising author; ${ }^{+}$Corresponding author
Keywords: arylsalylamides, production methods, structure and biological activity.
\end{abstract}

Abstract

Salicylamides ( $N$-aryl-substituted hydroxybenzamides): well-known organic compounds with diverse biological activity, which were originally investigated as antimicrobial and antifungal substances. Salicylamides have also been used as anthelmintic or molluscicidal agents in human and veterinary medicine. The most famous is 5,2'-dichloro-4'-nitrosalicylamide (niclosamide, yomezan - Germany), resynthesized in the USSR under the name of fenasal, which is effective in treating diphyllobothriasis and hymenolepidosis and has molluscicidal properties. The works of domestic and foreign scientists F.S. Mikhaylitsyn, H. Vanden Bosshe, L.M. Scheibel, P. Andreus, G. Bonse, and others are devoted to the synthesis of salicylamides, their biological activity. I. Arkhipov, R. Gonnert, studied the anthelmintic activity of salicylamides. E. Schraufstatter, H. Mrozik et al. In the works of various authors the "structure-activity linkage" of the synthesized amides is shown. It has been established that the presence of an amide or thioamide bond, substituted amides, is important for anthelmintic activity. The presence of a hydroxyl group in the 2nd position of the aromatic ring of the salicylamide acid fragment is the main condition for the manifestation of activity with respect to tape helminths and trematodes. The best profile of the biological activity of salicylamides was obtained by introducing chlorine into various positions of acid and amine fragments. Acylation of the hydroxyl group in salicylamides leads to a decrease in their toxicity.

\section{References}

[1] J.D. Williams. Vital antimicrobials recommended by WHO. Clinical Microbiology and Antimicrobial Chemotherapy. 2000. Vol.2. No.1. P.37-46. (russian)

[2] On the state of sanitary and epidemiological welfare of the population in the Russian Federation in 2014: State report. Moscow: Federal Service for Supervision of Consumer Rights Protection and Human Welfare. 2015. 206p. (russian)

[3] V.P. Sergiev, Yu.V. Lobzin, S.S. Kozlov. Parasitic diseases of man (protozoa and helminthiasis): A guide for doctors. St. Petersburg: Publishing Publishing LLC. 2008. 592p. (russian)

[4] V.P. Sergiev. Parasitic diseases today and tomorrow. Quality of life: Medicine. 2005. No.1. P.10-15. (russian)

[5] A.Ya. Lysenko, M.G. Vladimova, A.V. Kondrashin, J. Majori. Clinical parasitology: a guide. Geneva: WHO. 2002. 752p. (russian)

[6] Yu.V. Marushko, M.G. Gracheva. The current state of the problem of helminthiasis in children. Issues of Diagnosis and Treatment. Modern Pediatrics. 2012. No.43. P.21-26. (russian)

[7] C. Díez-Morrondo, R. Sánchez-Andrade, P. Ibaseta, J.L. Suárez, I. Francisco et al. A case-control study to analyze the influence of the environment in human sensitization against helminth parasitic antigens. Rev. Ibero-Latinoam. Parasitol. 2010. No.69(1). P.38-44.

[8] M.N. Lebedeva, N.B. Lopatina, T.B. Kralko. Market research of the Russian market of anthelmintic drugs assortment analysis. Medical Parasitology and Parasitic Diseases. 2001. No.2. P.48-51. (russian)

[9] M.N. Lebedeva, F.S. Mikhailitsyn, V.P. Sergiev. The creation of domestic antiparasitic drugs. Medical Parasitology and Parasitic Diseases. 2001. No.4. P.13-16. (russian)

[10] S.A. Mikhailova, L.A. Zolotukhina, N.A. Andreeva. Analysis of the regional market of antihelminthic drugs. Modern Problems of Science and Education. 2015. No.3.; URL: http://www.scienceeducation.ru/ru/article/view?id=20335 
[11] A. Imramovsky, K. Pauk, V. Pejchal, J. Hanusek. Salicylanilides and their derivates as perspective antituberculosis drugs: synthetic routes and biological evaluations. Journal of Organic Chemistry. 2011. Vol.8. P.211-220.

[12] L.N. Punegova, I.I. Kurbanova, T.S. Shitova, O.G. Sinyashin, and V.A. Alfonsov. Effect of structure and physico-chemical characteristics of veterinary medicines Vetameks and Melapol plus containing synthetic melatonin on their ability to prolonged action. Butlerov Communications. 2014. Vol.38. No.5. P.13-18. ROI: jbc-02/14-38-5-13

[13] T.V. Bolotova, V.A. Ermokhin, E.A. Mikha, A.S. Gilmutdinova, and P.P. Purygin. Synthesis of amino acid acetylsalicylates. Butlerov Communications. 2017. Vol.49. No.3. P.114-118. DOI: 10.37952/ROI-jbc01/17-49-3-114

[14] N.M. Storozhok, and N.P. Medyanik. Amid derivatives of salicylic acid - effective inhibitors of UV initiated oxidation of organic substrates. Butlerov Communications. 2017. Vol.50. No.6. P.22-29. DOI: 10.37952/ROI-jbc-01/17-50-6-22

[15] N.M. Storojok, N.P. Medyanik, S.A. Krekov, and A.P. Krisin. The supramolecular organization Nreplaced amides of salicylic acid. Butlerov Communications. 2011. Vol.24. No.3. P.109-112. ROI: jbc02/11-24-3-109

[16] A. Imramovsky, J. Vinsova, J.M. Ferriz, V. Buchta, J. Jampilek. Salicylanilide esters of N-protected amino acids as novel antimicrobial agents. Journal of Bioorganic \& Medicinal Chemistry Letters. 2009. Vol.19. P.348-351.

[17] J. Matyk, K. Waisser, K. Drazkova, J. Kunea, V. Klimesova, K.Jr. Palat, J. Kaustova. Heterocyclic isosters of antimycobacterial salicylanilides. Farmaco. 2005. Vol.60. P.399-408.

[18] J. Vinsova, A. Imramovsky, V. Buchta, M. Ceckova, M. Dolezal, F. Staud, J. Jampilek, J. Kaustova. Salicylanilide acetates: synthesis and antibacterial evaluation. Molecules. 2007. Vol.12. P.1-12.

[19] K. Waisser, M. Peina, V. Klimeová, J. Kaustová. On the relationship between the structure and antimycobacterial activity of substituted $N$-benzylsalicylamides. Collection of Czechoslovak Chemical Communications. 2003. Vol.68. P.1275-1293.

[20] P. Skala, M. Machacek, M. Vejsova, L. Kubicova, J. Kunes, K. Waisser. Synthesis and antifungal evaluation of hydroxy-3-phenyl-2H-1,3-benzoxazine-2,4(3H)-diones and their thioanalogs. Journal of Heterocyclic Chemistry. 2009. Vol.46. P.873-880.

[21] X. Zhu, Q.S. Yu, N.H. Greig, J.L. Flippen-Anderson, A.A. Brossi. Simple one-pot synthesis of benzoxazine-2,4-diones and benzothiazine-2,4-diones. Journal of Heterocyclic Chemistry. 2003. Vol.59. P.115-128.

[22] R. De La Fuente, N.D. Sonawane, D. Arumainayagam, A.S. Verkman. Small molecules with antimicrobial activity against $\mathrm{E}$. coli and $\mathrm{P}$. aeruginosa identified by high-throughput screening. British Journal of Pharmacology. 2006. Vol.149. P.551-559.

[23] A.X. Lupea, L. Popescu, C. Tarabasanu. Synthesis of new 2-[2-(4-chlorophenylcarbamoyl)]phenoxyalkanoic acid derivates. Revue Roumaine de Chimie. 2006. Vol.51. P.517-521.

[24] G. Nawwar, L.M. Chabaka, N.A. Shafik. Oximinosalicylanilide like analogues as molluscicidal agents. Afinidad. 2006. Vol.63. P.153-158.

[25] I.A. Arkhipov. Anthelmintics: pharmacology and application. Moscow: Russian Agricultural Academy Printing House. 2009. 406p. (russian)

[26] S. Sharma, N. Anand. Approaches to design and synthesis of antiparasitic drugs. Pharmacochemistry Library. 1997. Vol.25. P.239-257.

[27] D.P. Sevbo, A. Malakhova, and V.N. Kuklin. Synthesis, the structure of arylsalicylic amides, which have anthelmintic activity. Butlerov Communications. 2017. Vol.51. No.9. P.115-124. DOI: 10.37952/ROI-jbc-01/17-51-9-115

[28] D. Gong, J. Li, C. Yuan, J. Yuan. Synthetic study of substituted arylsulfonylphenylbenzamides. Journal of Synthetic Communications. 2005. Vol.35. P.55-66.

[29] W. Deng, Z. Guo, Z. Feng, Y. Juany, F. Chu. Acryloylaminosalicylanilides as EGFR PTK inhibitors. Journal of Bioorganic \& Medicinal Chemistry Letters. 2006. Vol.16. P.469-472.

[30] Patent 2370484 Russian Federation, IPC C07C233 / 66, AK 31/609, A61P 33/10. Anthelmintic agent based on N-(3-chloro-4-methylphenyl)-3,5-dibromosalicylamide. D.P. Sevbo, E.I. Sakanyan, S.N. Trusov, F.S. Mikhaylitsyn, I.A. Arkhipov, A.V. Radionov, N.I. Koshevar; applicant and patent holder of GOU VPO SPHFA of Roszdrav. No. 2008112830/04; declare 04/02/2008; publ. 10/20/2009, Bull. No.29. 7p. (russian) 